\title{
Plowing for Rover Control on Extreme Slopes
}

\author{
David Kohanbash \\ Submitted in partial fulfillment of the requirements of Masters of
}

Science in Robotics

December 2011

CMU-RI-TR-11-35

Robotics Institute

Carnegie Mellon University

Pittsburgh, Pennsylvania 15213

Masters Committee:

David Wettergreen (Chair)

William "Red" Whittaker

Scott Moreland

(c) David Kohanbash and Carnegie Mellon University 



\section{Abstract}

Planetary rovers are increasingly challenged to negotiate extreme terrain. Early destinations have been benign to preclude risk, but canyons, funnels, and newly discovered holes present steep slopes that defy tractive descent. Steep craters and holes with unconsolidated material pose a particularly treacherous danger to modern rovers. This thesis explores robotic braking by plowing, a novel method for decreasing slip and improving mobility while driving on steep unconsolidated slopes. This technique exploits subsurface strength that is under, not on, weak soil. Starting with experimental work on Icebreaker, a tracked rover, and concluding with detailed plow testing in a wheel test-bed the plow is developed for use. This work explores using plows of different diameters and at different depths as well as the associated braking force. By

plowing the Icebreaker rover can successfully move on a slope with a high degree of accuracy thereby enabling science targets on slopes and crater walls to now be considered accessible. 



\section{Contents}

1 Abstract I

2 Introduction 1

2.1 Motivation . . . . . . . . . . . . . . . . . . 1

2.2 Background ..................... 1

2.3 Research Assertion . . . . . . . . . . . . . . . . . 3

3 Background 3

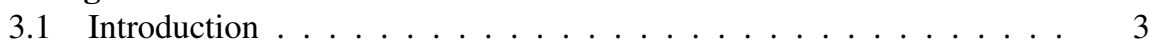

3.2 Prior Research in Plowing . . . . . . . . . . . . . . . . 4

3.3 Prior Icebreaker Work . . . . . . . . . . . . . . . . . . . . . . 7

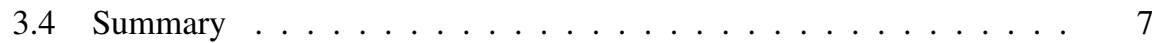

4 Rover Testing 8

4.1 Introduction . . . . . . . . . . . . . . . . . . . 8

4.2 Icebreaker Rover . . . . . . . . . . . . . . . . . . 8

4.3 Experiment Design . . . . . . . . . . . . . . . . . . 9

4.3.1 Descent . . . . . . . . . . . . . . . . . . . . 9

4.3.2 Drawbar Pull . . . . . . . . . . . . . . . . . . . . 10

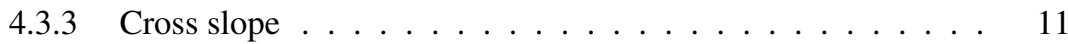

4.3 .4 Point turns . . . . . . . . . . . . . . . . . . . . . 12

4.4 Experimental Results . . . . . . . . . . . . . . . . . . . . . 12

4.4 .1 Descent . . . . . . . . . . . . . . . . . 12

4.4 .2 Drawbar Pull . . . . . . . . . . . . . . . . . . 12

4.4 .3 Cross Slope . . . . . . . . . . . . . . . . . . . . 12

4.4 .4 Point Turns . . . . . . . . . . . . . . . . . . . . . . . . 14

4.5 Rover Comparison . . . . . . . . . . . . . . . . . . . 15

4.6 Summary . . . . . . . . . . . . . . . . . . . 16

5 Plow Analysis 19

5.1 Introduction . . . . . . . . . . . . . . . . . . 19

5.2 Experiment Design $\ldots \ldots \ldots \ldots \ldots \ldots$

5.3 Model Results . . . . . . . . . . . . . . . . . . . . . . . . . 20

5.4 Experimental Results . . . . . . . . . . . . . . . . . . 20

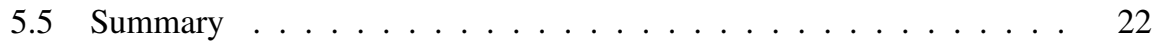

6 Conclusion 25

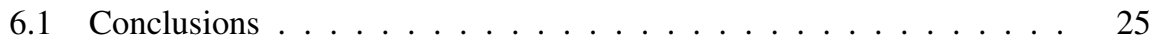

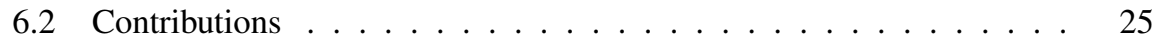

6.3 Future Work . . . . . . . . . . . . . . . . . . 25

6.4 Acknowledgements . . . . . . . . . . . . . . . 26 



\section{Introduction}

\subsection{Motivation}

The robotic exploration of planetary bodies requires rovers that can safely explore its environment and have the ability to reach points of scientific interest. Rovers significantly expand the possible exploration areas and increase the scientific and programmatic return from a mission. The surface of the moon and planets such as Mars are covered in fine and unconsolidated regolith making mobility considerations of utmost importance[13]. There are many craters and steep slopes that are also covered in this fine and unconsolidated regolith. The ability to traverse steep slopes, funnels, and holes becomes even more compelling in the case of Mars where there is now evidence of new deposits forming on the side of crater walls (Figures 1 and 2) [1] and in the case of the moon with resources in permanently shadowed polar craters. Many of these crater walls have slopes that exceed of 25 degrees [5] [22].

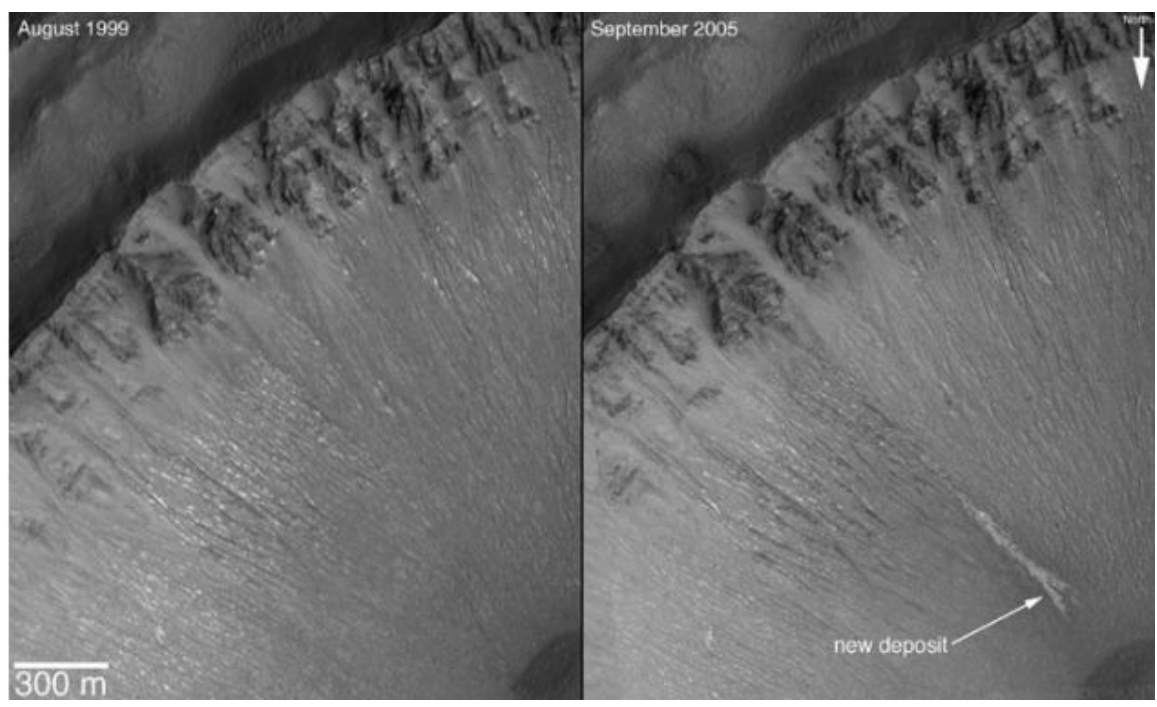

Figure 1: New deposits found on a crater wall in Centauri Montes [1].

\subsection{Background}

In this work a plow mechanism is tested both on a rover named Icebreaker as well as in a wheel test-bed to throughly characterize how a plow can be used for increased control authority on a slope.

The "plow" is a dagger like rod that is driven into the ground by a robot to create a braking force by exploiting the subsurface soil strength (Figure 3). This braking force is used to counter downhill forces in order to minimize slip. The plow is a circular rod located at the center point of the robot to facilitate turning. This is a mechanical analog to a climbers use of a handle or pole to arrest or control a slide. The plow on 


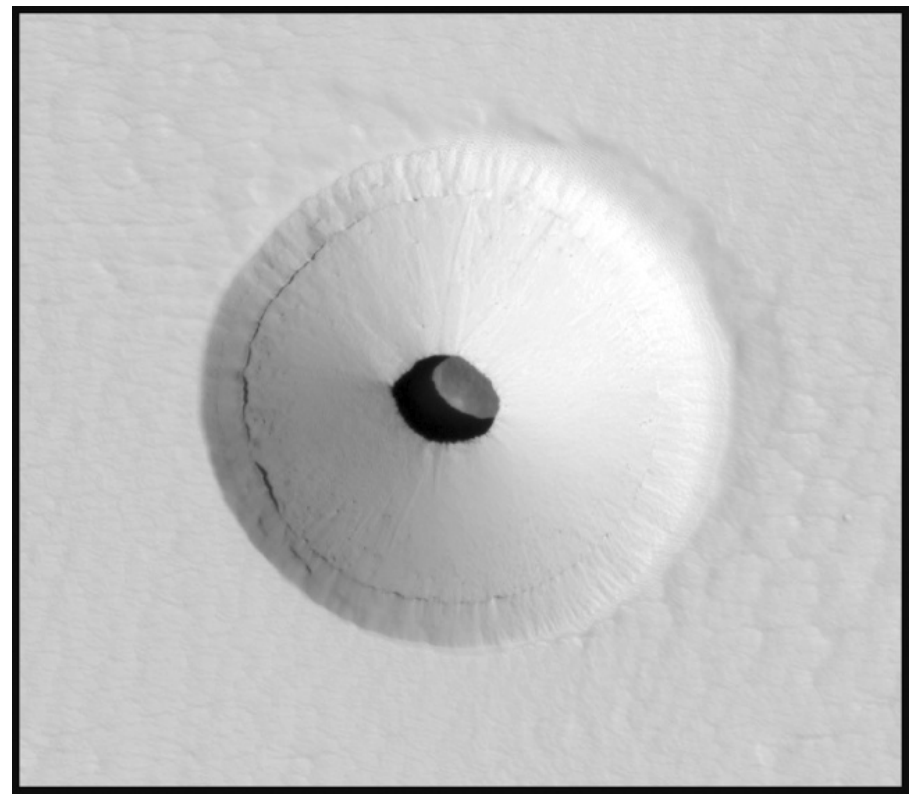

Figure 2: Pit on Mars. Pit has a diameter of 195 meters and a depth of 50 meters. There is an interesting skylight in the center [6].

the rover is actuated using a rack and pinion and has a lexan tip to help the plow pierce the ground to minimize vertical plow forces (Figure 4).

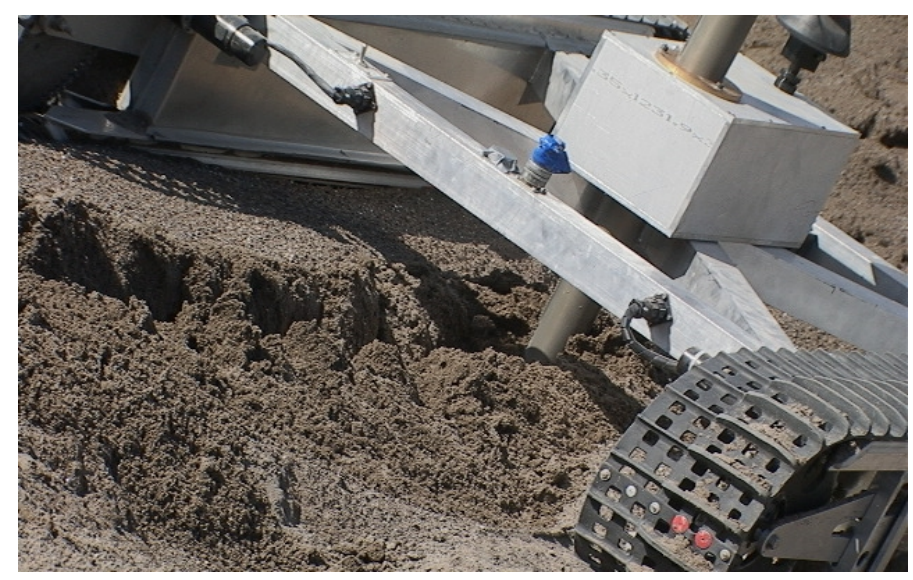

Figure 3: Icebreaker actuated plow. The box contains the motor and pinion for driving the plow into the ground [28].

It is generally recognized that the interaction of the rover and the terrain is complex and difficult to model. In addition, standard models do not work in very unconsolidated 


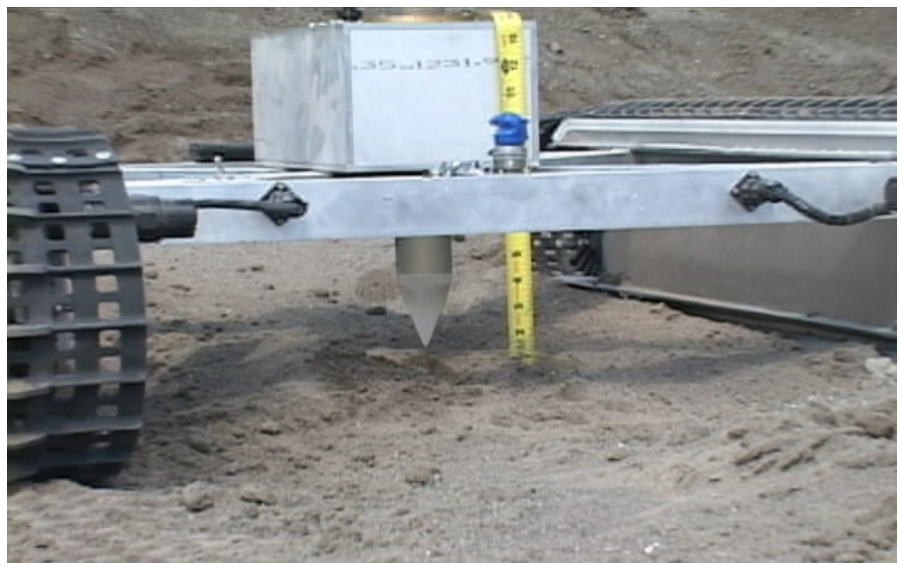

Figure 4: Icebreaker actuated plow. Conical lexan tip is used to penetrate into the ground [28].

material with low moisture levels [25]. Prior work with model based terrain controls have problems with accurately modeling the terrain and seek better methods to simulate the wheel/terrain interaction [7][12]. For these reasons having a device that is purely reactionary and not dependant on possibly inaccurate models is important.

Work with the plow mounted to the Icebreaker rover demonstrates proof of concept that a plow can reduce slip while operating on a slope. Work then continues in an instrumented sand box to further quantify plow performance to determine braking force provided by the plow as well as how plow diameter and plow depth affects braking force.

\subsection{Research Assertion}

This research asserts that plowing to engage below the driving surface is a means for controlling robotic descent beyond limits of what is possible through traction.

\section{Background}

\subsection{Introduction}

There are many approaches that have been proposed for descending and maneuvering on steep planetary slopes [4]. Examples include tumbling(rolling), walking [3], driving [23], tethered [1] as well as hybrids of these approaches. Each of these approaches has positive and negative attributes. For example a tethered robot is able to descend vertical faces, however it also has the ability for the tether to snag and has difficulty moving across the slope as the tether only supports motion in one axis. 


\subsection{Prior Research in Plowing}

The crux of this research is the plow. There are no direct analogies in planetary robotics, however there are examples in other fields and in particular farming. In farming tines (Figure 5) which are similar to the plow used in this work have been studied. It is important to note that most tools that interact with the ground have been designed more on the basis of field experience than on scientific knowledge since soil-tool interaction is not well defined and quantified [21]. The major variables in tine research is size, depth, tine speed, and soil moisture. There are many models that try and explain this, however they are very specific to the soil tested in and other specific test conditions. It was found that soil moisture and shear strength have the largest impact on the soil forces and at small speeds the affect of speed can be neglected [8]. In low moisture content soils the Mohr-Coulomb criterion applies however in sand with a large moisture content there is increased variability[20]. The disturbance pattern in the soil has been shown to be repeatable in a wide range of materials and soil moistures for a given tine design[9].

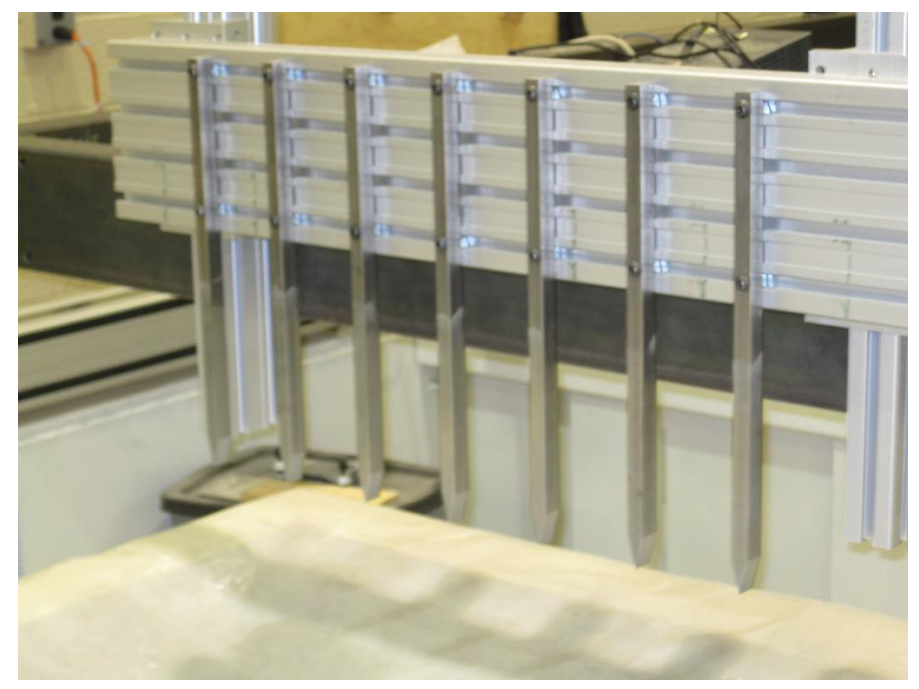

Figure 5: Multiple tines attached to a bar.

The Mohr-Column law predicts a linear increase in force with depth. There are two distinct depths that need to be considered. Anything above the critical depth results (Figure 6) in brittle failure which does not provide much resistance force, this is deemed crescent failure where the disturbed soil is pushed to the sides, in front, and upward. Below the critical depth results in the surrounding soil in the direction of motion to compact thereby providing the subsurface strength that is needed for plowing. This is called lateral failure (Figure 7) [8]. In practice the critical depth is hard to find. The best way to find it is in a glass sided sand box where the groove from the plow track is visible and can be measured, there are also iterative mathematical models that can provide a rough estimate of the critical depth by using force models and trying to 
estimate the critical depth parameter[17]. In practice people make the assumption that the critical depth is six times the width of the tine [16]. It should be pointed out that this assumption is in standard field conditions which are not dry unconsolidated fine sands as experienced in this research and has a high error. In theory this means that in order to have a significant subsurface strength the plow depth needs to be deeper than this critical depth.

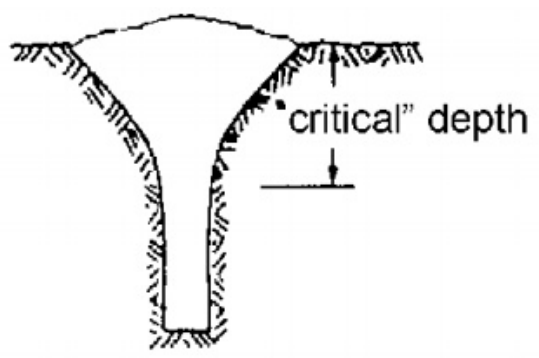

Figure 6: Critical depth in plow track [8].

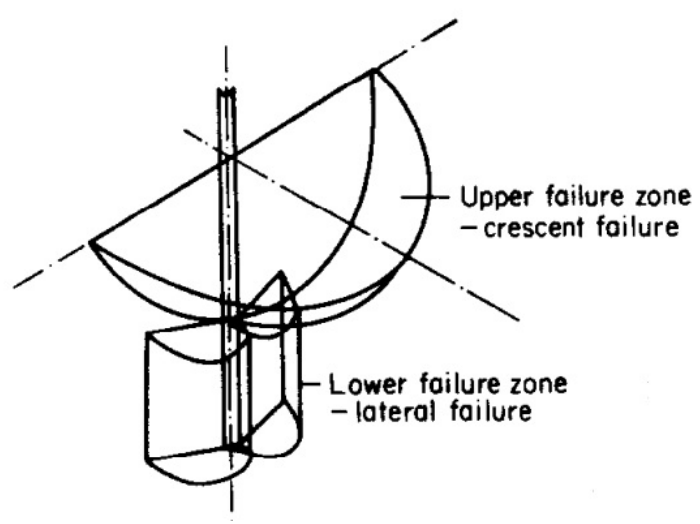

Figure 7: Both soil failure modes of a tine are shown [17].

Godwin and O'Dogherty developed a model for very thin tines that is applicable to the plow. Using figure 8, $\mathrm{H}$ is the force in the crescent portion of the failure above the critical depth and Q is the force in the lateral failure below the critical depth. $\mathrm{H}_{T}$ is the total force from the tine[18]. Using this model we can estimate the forces on the plow based on different plow diameters and depths as well as in different ground conditions.

The other area of this design that directly affects mobility is the tracked mobility system on the rover. There is a lot of research that discusses tracked vehicles[15][24] and some research that discusses surface soil shearing from tracked rovers[25]. Ishigami [12] [13] looks at side forces on the track which is very important when operating on slopes. This research shows that bulldozing resistance is generated per unit width of 


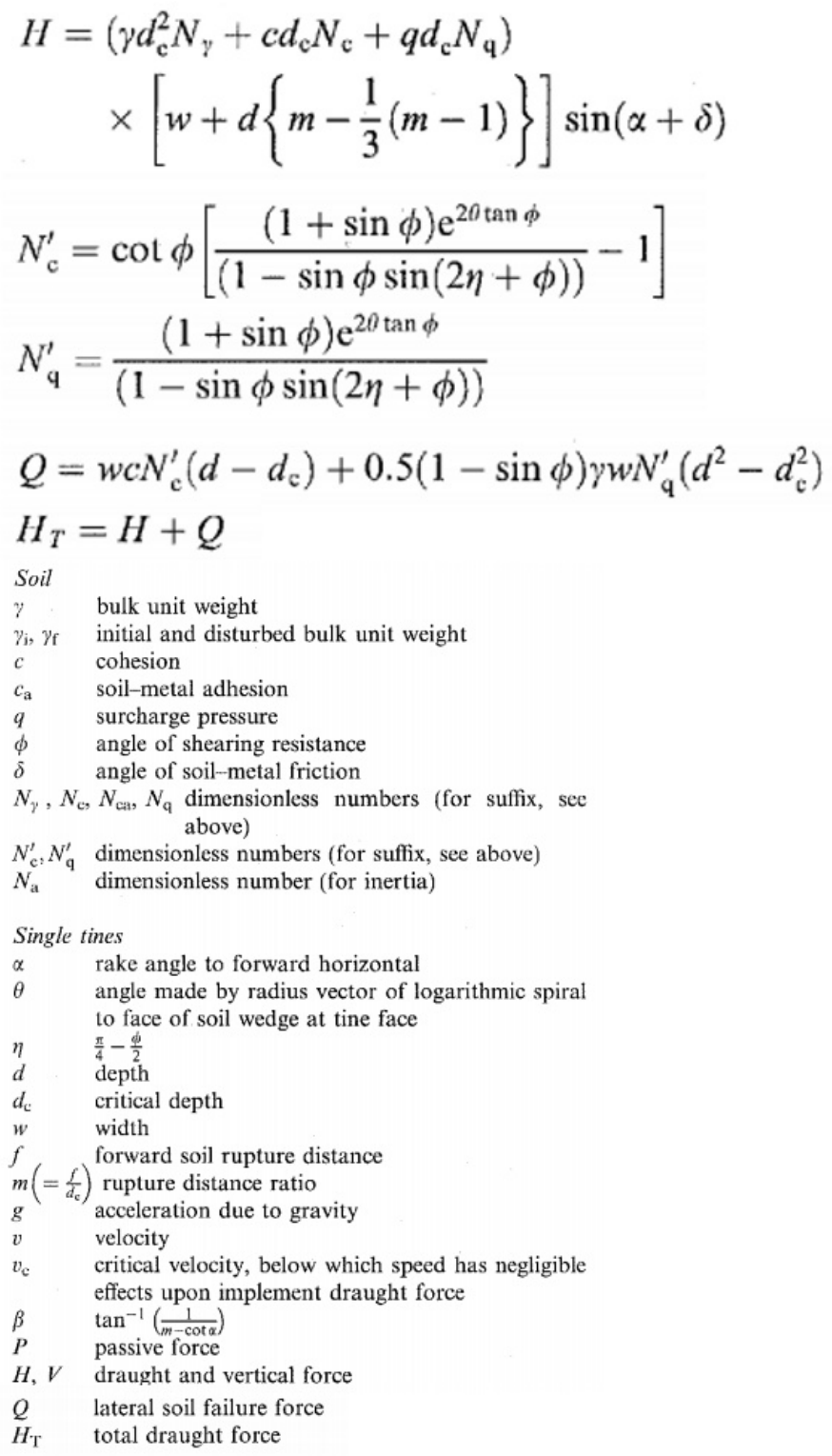

Figure 8: Tine force equation from Godwin for single very narrow tine (ie plow). $\mathrm{H}_{T}$ is the total force and $\mathrm{H}$ and $\mathrm{Q}$ are the two sub-components of the force for each failure mode [18].

the blade that moves towards the soil. When turning on a slope there is a significant bulldozing affect on the side of the track that directly affects mobility as well as vehicle 
power.

\subsection{Prior Icebreaker Work}

Prior testing with Icebreaker showed the necessity of having controlled mobility on steep unconsolidated slopes. On 35 degree slopes and steeper soil shear failure created an avalanche affect that would bring the rover to the bottom of the hill at the beginning of any rover motion when the plow was not in use. Field testing conducted at a slag heap showed unprecedented control on steep unconsolidated slopes when using the plow. For linear descent the use of a plow reduced slip by almost twenty-fold (Figure 9) and three-fold for point turns (Figure 10). Qualitative observations showed that total slip while driving large arcs with no plow had a much higher slip than driving a point turn with the plow[27] [29].

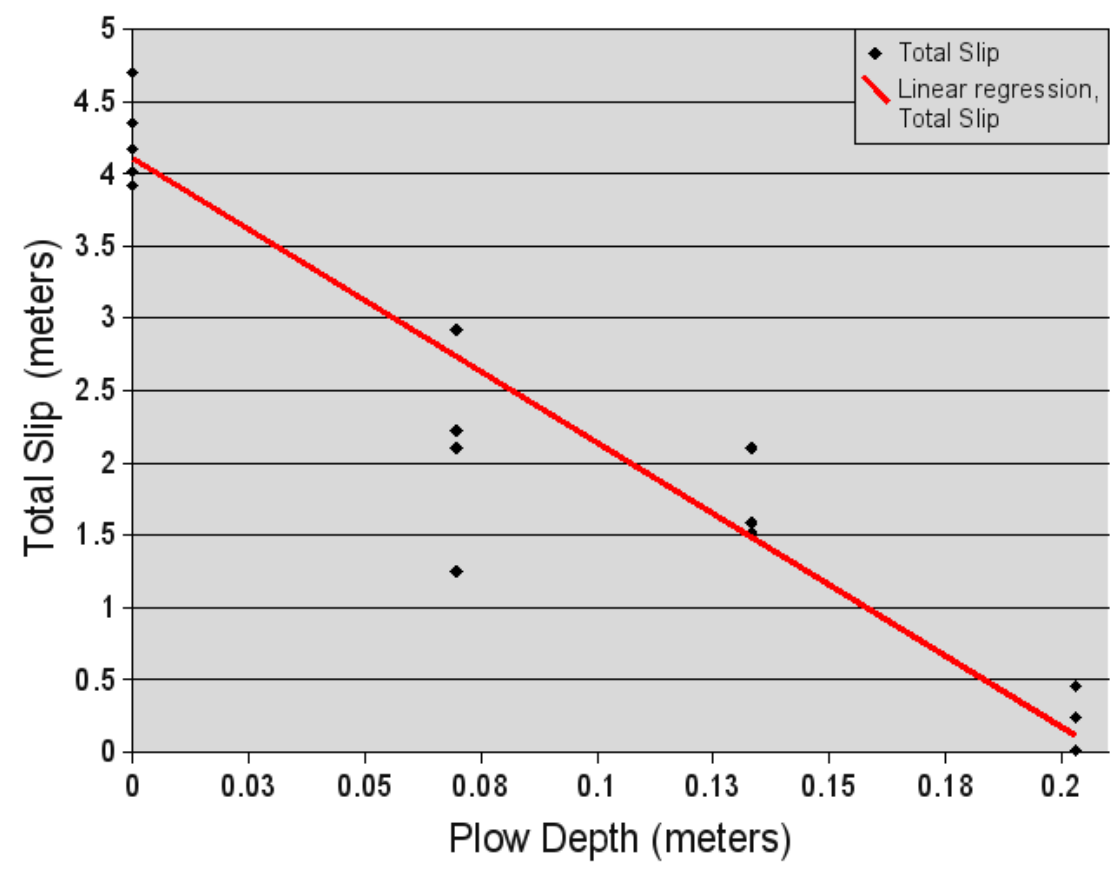

Figure 9: Icebreaker linear descent while utilizing the plow on a 38 degree slope. [29].

\subsection{Summary}

Prior work in related fields provides an insight into how the plow will perform and where the forces are coming from. The prior work with Icebreaker in uncontrolled earth field sites demonstrates that plowing works. This work is going to combine these two aspects to quantify the plow and test Icebreaker in planetary analog conditions. 


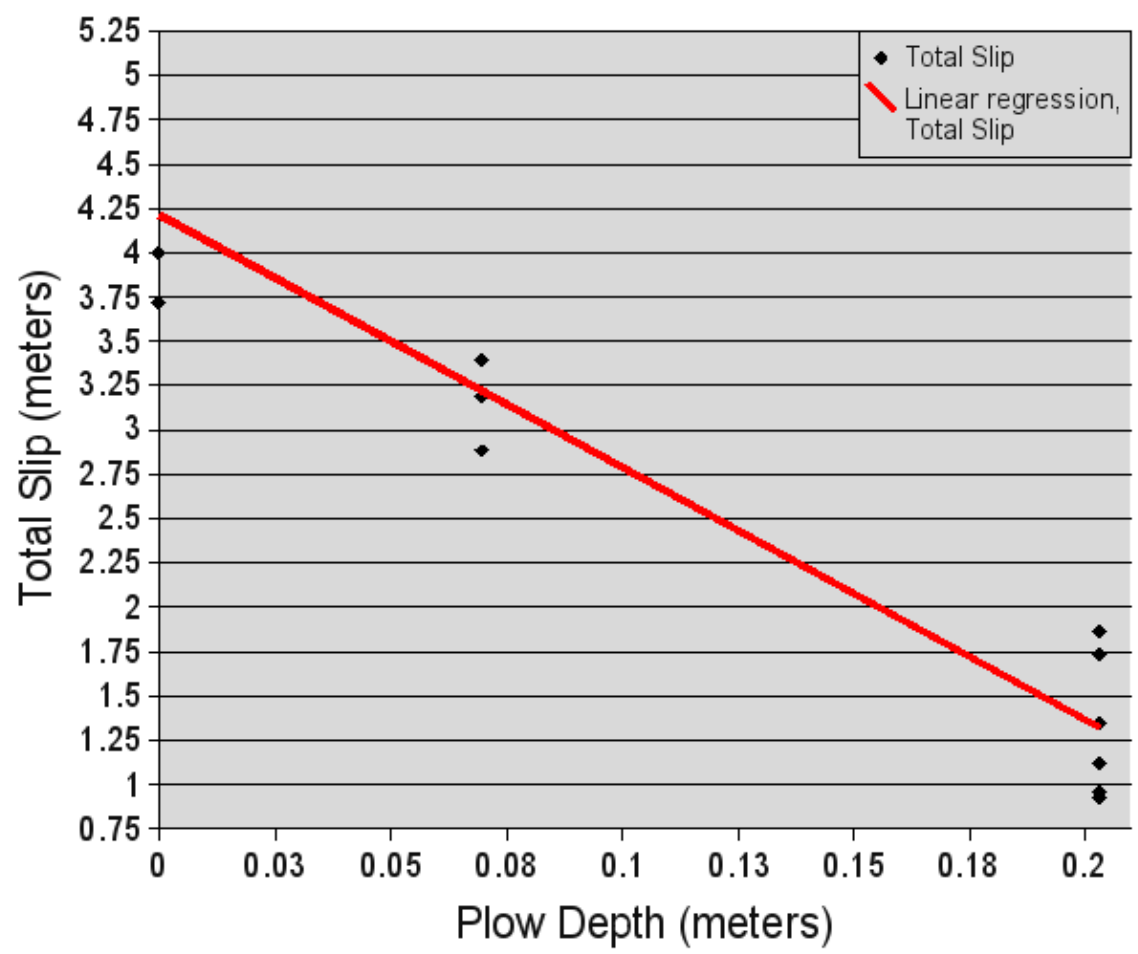

Figure 10: Icebreaker point turning while utilizing the plow on a 38 degree slope. [29].

\section{Rover Testing}

\subsection{Introduction}

Rover testing is conducted with the plow to demonstrate and quantify the plow and almost more importantly the plow and vehicle joint interaction. By testing on a rover we can provide real evidence that plowing works and is a viable solution.

\subsection{Icebreaker Rover}

Icebreaker is a prototype rover designed to traverse into steep planetary craters. The rover is $70.4 \mathrm{~kg}$ with $47.9 \%$ of the weight to the left and $55.0 \%$ to the rear. It is 1.1 meters wide and 1.4 meters long. The top of the rover deck is $22 \mathrm{~cm}$ from the ground. It is a tracked rover since tracks can offer the best solution for operating over complex terrain. This is especially important for steep and loose slopes [19]. The chassis provides a rigid frame to which the tracks are attached and the plow is mounted to. The plow is mounted $11 \mathrm{~cm}$ from the center of the rover and is actuated to allow for easy plow adjustments (some work has been done creating a slip controller to dynamically adjust the plow). The tip of the plow has a lexan cone which is needed to help pierce 
into the soil and proceed with lowering the plow further into the ground. All of the electronics and batteries for the rover are contained within the track side frame. This helps the rover maintain a very low center of gravity at $13.2 \mathrm{~cm}$ from the ground.

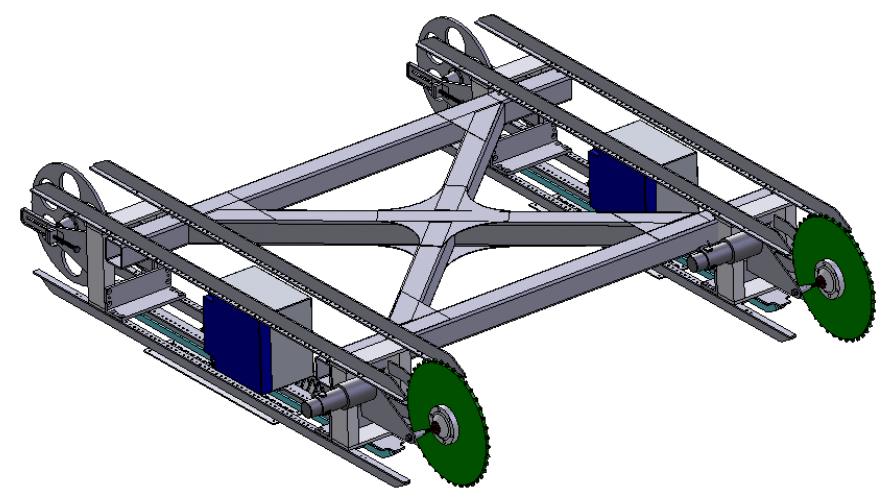

Figure 11: Icebreaker chassis with tracks removed [29].

\subsection{Experiment Design}

Testing with Icebreaker was conducted at the Simulated Lunar Operations (SLOPE) facility at the NASA Glenn Research Center in Ohio. The SLOPE facility has a large sandbox of GRC-1 lunar simulant that is capable of tilting to 30 degrees. The soil is prepared using a standard method called T3 [26] to achieve conditions similar to the lunar terrain[10]. This process involves using a shovel to disturb and loosen the subsurface soil where the rover will be operating and then it is smoothed lightly using a rake to insure uniform conditions for the test. A Leica TCRA1103+ Total Station is used to track the rovers position with high accuracy in order to determine slip (Figure 12). There is also an adjustable load system and a load cell for conducting drawbar pull tests (Figure 13).

Four types of tests were conducted at the SLOPE test facility decent, drawbar pull, cross slope, and point turns. A driving test on flat simulant was done to confirm that there is no bias between the tracks and to get the speed differential between commanded and actual drive distance. Before starting the tests it was qualitatively observed that the vehicle had minimal slip at around $17 \mathrm{~cm}$ plow depth. In order to bound this testing was done at $14 \mathrm{~cm}$ and $20 \mathrm{~cm}$ plow depth and then at $7 \mathrm{~cm}$ plow depth to bridge the gap from $0 \mathrm{~cm}$ to $14 \mathrm{~cm}$ in many of the tests. The plow used in this test is 2 inches in diameter and the vehicle moved at $0.2 \mathrm{~m} / \mathrm{s}$.

\subsubsection{Descent}

Descent tests were done with Icebreaker on a slope at 31 degrees (Figure 14) with plow depths of $0 \mathrm{~cm}, 7 \mathrm{~cm}, 14 \mathrm{~cm}$, and $20 \mathrm{~cm}$ where $0 \mathrm{~cm}$ is plow disengaged and $20 \mathrm{~cm}$ is the plow fully embedded into the ground. This gives a clean comparison of vehicle performance and how the plow improves mobility. 


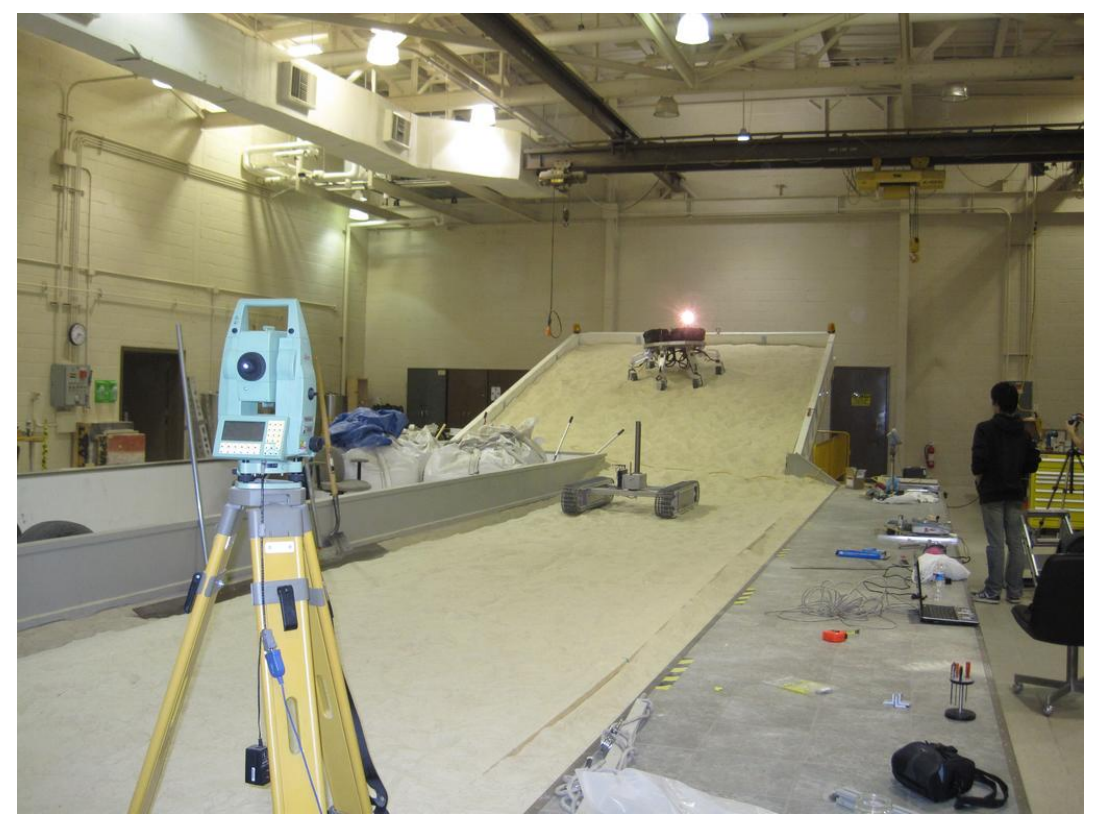

Figure 12: Test setup with surveying instrument (on the left) and prism (bright spot) mounted on a rover at NASA GRC SLOPE facility.

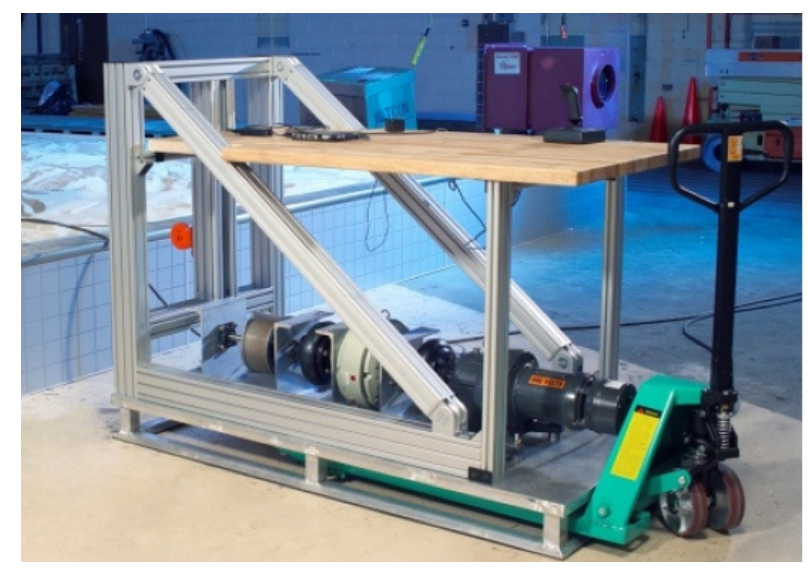

Figure 13: Drawbar pull rig with adjustable load at the SLOPE facility[26].

\subsubsection{Drawbar Pull}

Drawbar pull tests were conducted with various loads at the four plow depths. For this test the drawbar pull rig at NASA Glenn Research Center was used. This rig allows for an adjustable load to be applied to the rover and for recording of vehicle position. A load cell was attached between the rover and the adjustable load rig. This helps us 


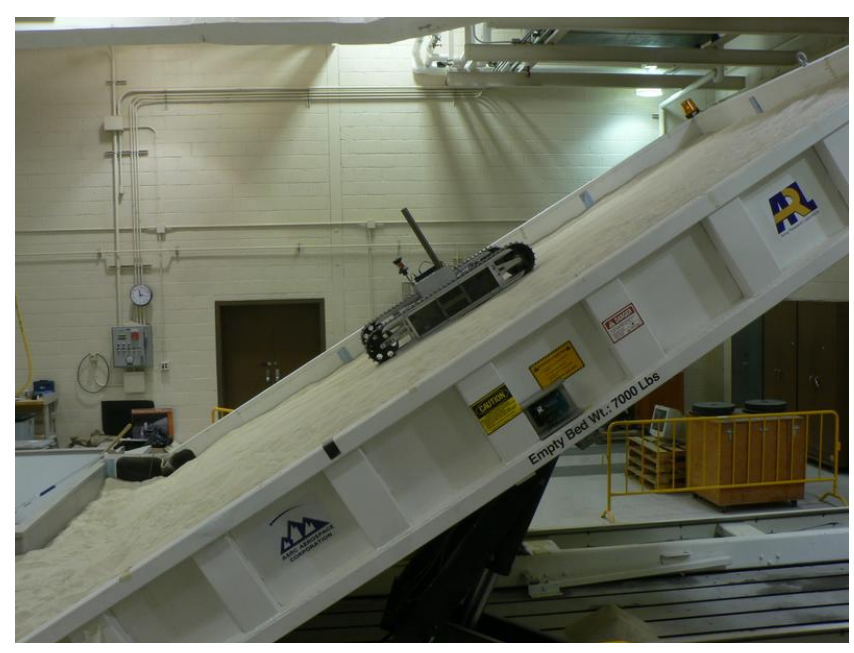

Figure 14: Descent test at 31 degrees.

understand the braking force being applied by the plow to the rover (Figure 15) and to charachterize the overall mobility system.

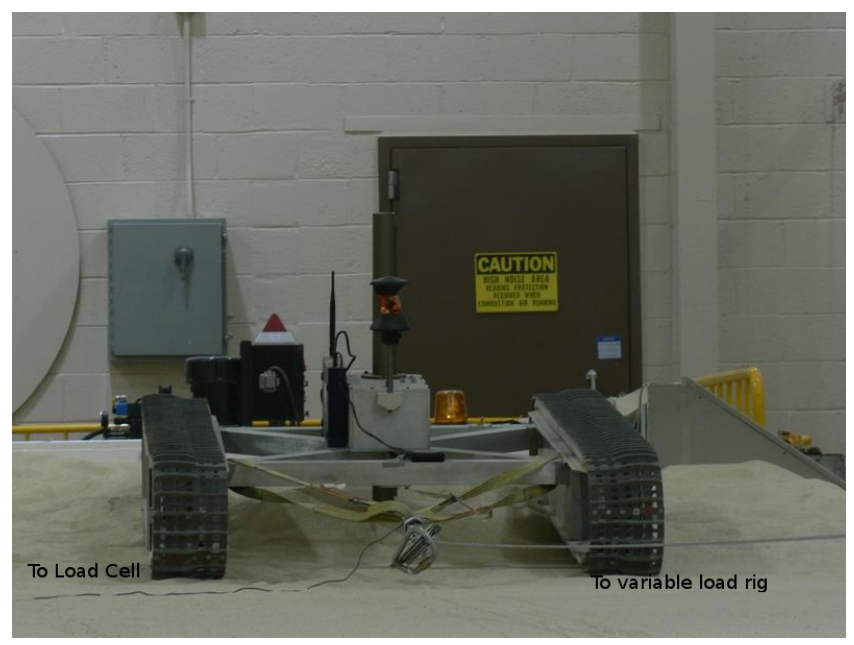

Figure 15: Draw bar pull test setup with lines going to a load cell and the variable load source.

\subsubsection{Cross slope}

Cross slope tests were done at slope angles of 10, 15, 20, 25, and 30 degrees with no plow engaged (Figure 16). 


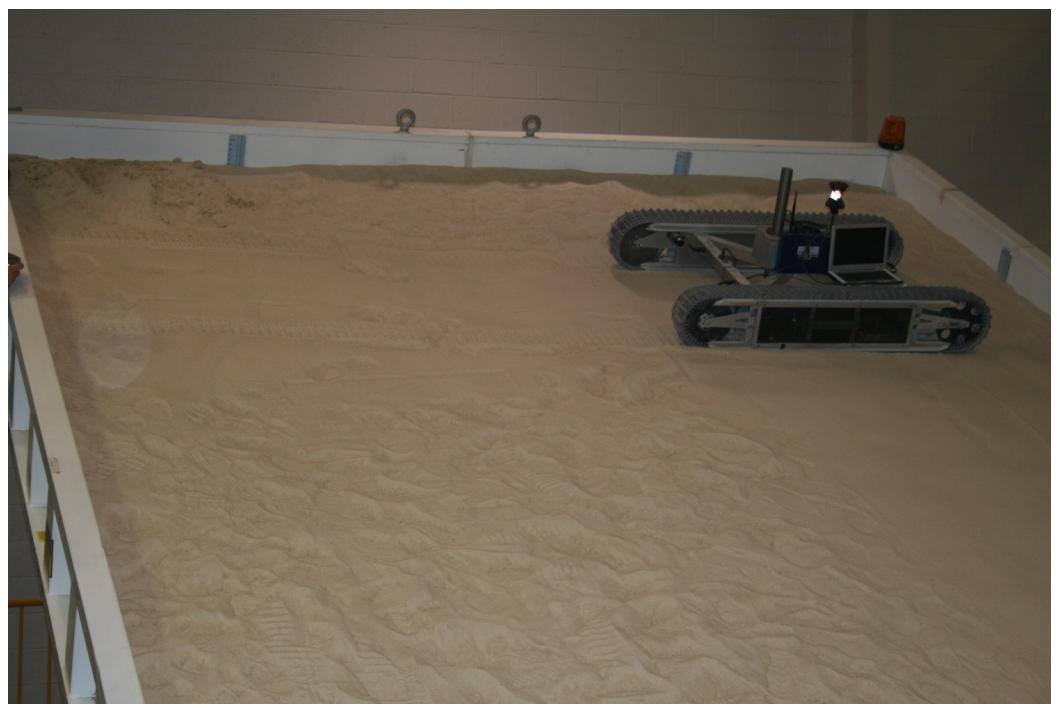

Figure 16: Cross Slope test at 30 degrees.

\subsubsection{Point turns}

Point turn tests were done at slope angles of 10, 15, 20, 25, and 30 degrees for each plow depth of $0 \mathrm{~cm}, 7 \mathrm{~cm}, 14 \mathrm{~cm}$, and $20 \mathrm{~cm}$. Figure 17 (a) shows how the rover is positioned to start a test, figure 17(b) shows the rover in the middle of a test as it is pointed at about 45 degrees, and figure 17(c) shows the position of the rover at the end of the test where it is pointed downhill.

\subsection{Experimental Results}

\subsubsection{Descent}

Descent tests exhibit an improvement as can be seen from having no plow where the rover slipped about $27 \mathrm{~cm}$ to when the plow is in the full $20 \mathrm{~cm}$ depth and acts like a brake to fully counteract the slip and even slightly impede rover motion (Figure 18).

\subsubsection{Drawbar Pull}

In the drawbar pull tests results are consistent with what was observed in the slope tests. The deeper the plow is into the ground the greater the resistance to slip at a given force. This becomes interesting for the $20 \mathrm{~cm}$ plow depth where at an applied force of $100 \%$ vehicle weight the rover still has trivial slip (Figure 19).

\subsubsection{Cross Slope}

The tracked rover demonstrates excellent cross slope abilities. Even at a 30 degree slope there is only 15\% downhill slip (Figure 20). 


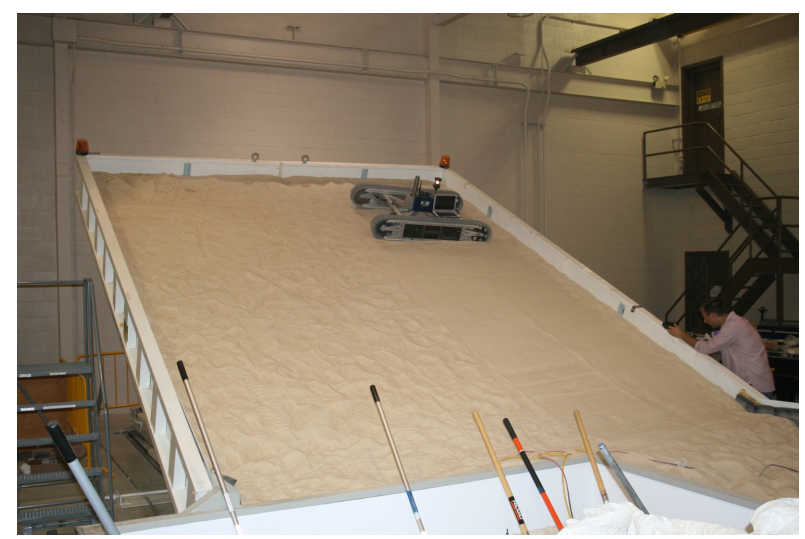

(a) Start Position

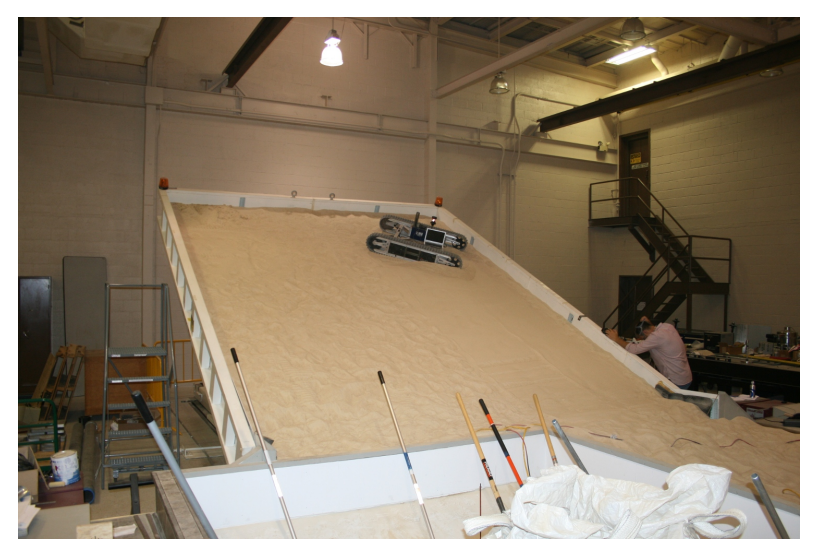

(b) Middle Position

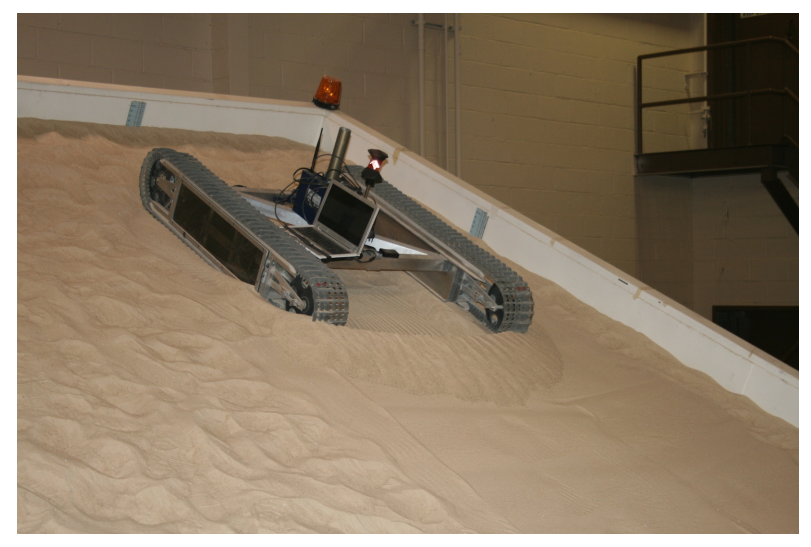

(c) End Position

Figure 17: Point turning test on 25 degree slope (clockwise rotation) 


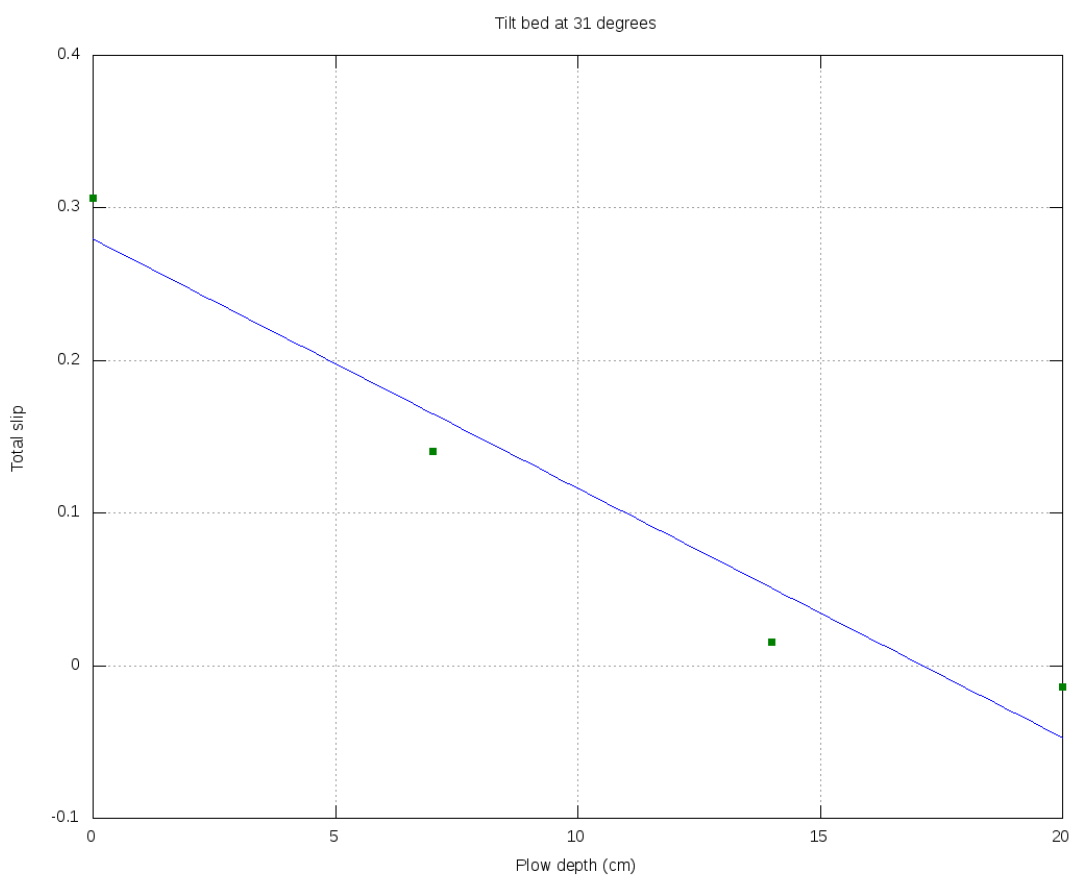

Figure 18: Descent tests on a 31 degree slope at 4 plow depths.

\subsubsection{Point Turns}

Point turning with the plow also has a tremendous influence (Figure 21). While with full plow depth all of the turns had less than $10 \mathrm{~cm}$ of slip the effects at the 30 degree maximum slope are the most telling. At 30 degrees with no plow the vehicle slipped 0.58 meters, however with the plow fully engaged the slip was only 0.077 meters (Table $1)$.

\begin{tabular}{|c|cccc|}
\hline Slope/Depth & $0 \mathrm{~cm}$ & $7 \mathrm{~cm}$ & $14 \mathrm{~cm}$ & $20 \mathrm{~cm}$ \\
\hline $10 \mathrm{deg}$ & 0.078 & 0.042 & 0.020 & 0.021 \\
$15 \mathrm{deg}$ & 0.177 & 0.114 & 0.035 & 0.030 \\
$20 \mathrm{deg}$ & 0.280 & 0.287 & 0.091 & 0.044 \\
$25 \mathrm{deg}$ & 0.445 & 0.384 & 0.253 & 0.056 \\
30deg & 0.580 & 0.553 & 0.413 & 0.077 \\
\hline
\end{tabular}

Table 1: Table with point turn values. 


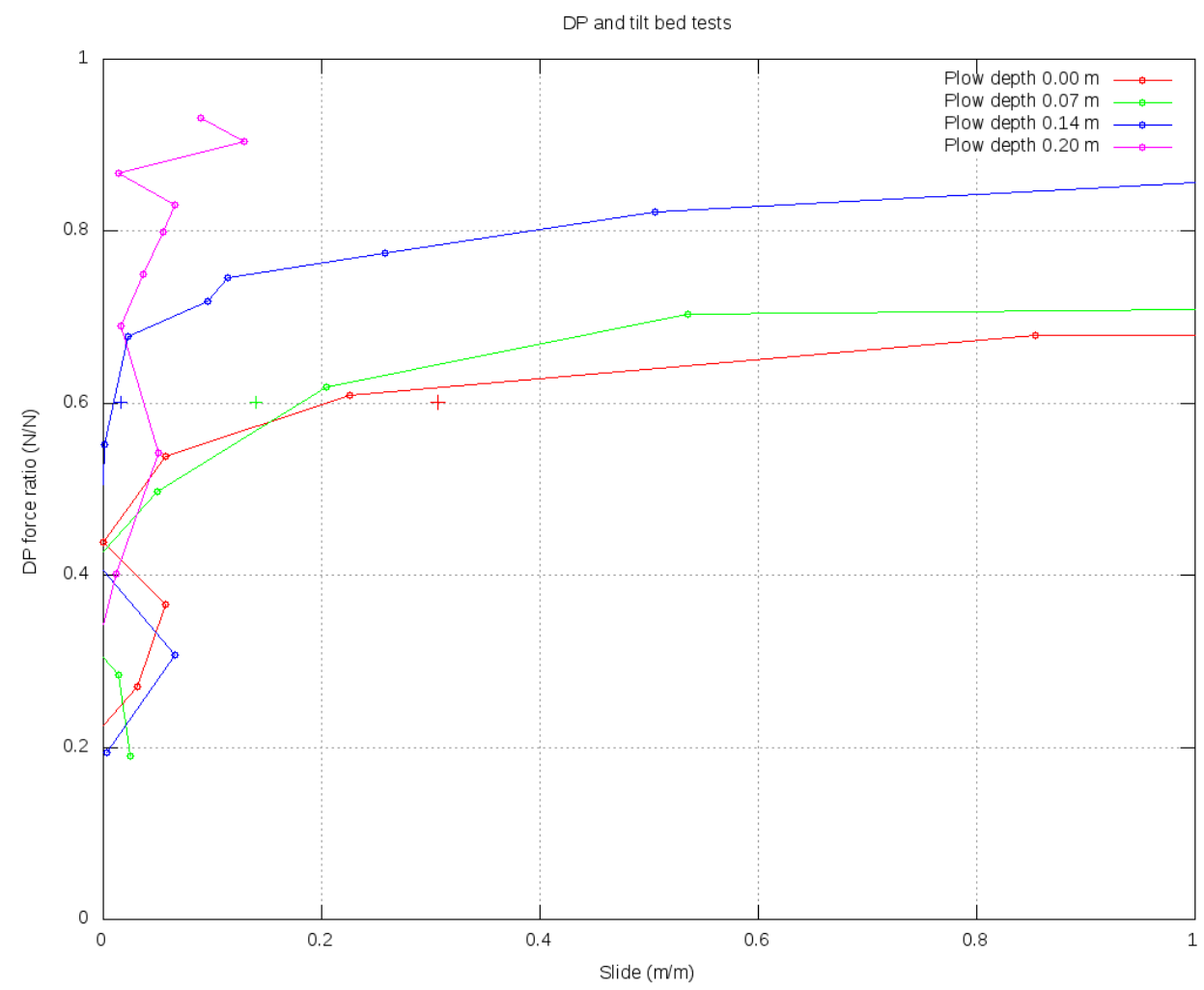

Figure 19: Drawbar pull with the plow at 4 depths. + points represent the slip values from the descent tests.

\subsection{Rover Comparison}

Using the results above, a comparison can be made with the MER rovers (Figure 22) Spirit and Opportunity that are currently on Mars. This acts as a review of not only the plow but also of tracked rovers such as Icebreaker in comparison to the MER rovers which have a six wheel rocker bogie. For downhill descent the MER rovers slip 55\% of distance traveled while on a 20 degree slope, however Icebreaker only slips $27 \%$ on a 31 degree slope with no plow. When the plow is utilized icebreaker does not exhibit any slip. The next item to compare is cross slope for a 20 degree hill the MER rovers slip almost $60 \%$ of total drive. Another robot Scarab a four wheel rover with an adjustable suspension has 37\% slip while cross sloping a 20 degree slope in a conventional manner. Scarab also has the ability to lean into the slope to control the body roll of the vehicle in this mode the slip is $15 \%$ [23]. Icebreaker with its tracks and very low center of gravity only slips $7 \%$ of distance traveled on a 20 degree slope. It is difficult to make a direct comparison between the two rovers for point turn tests 


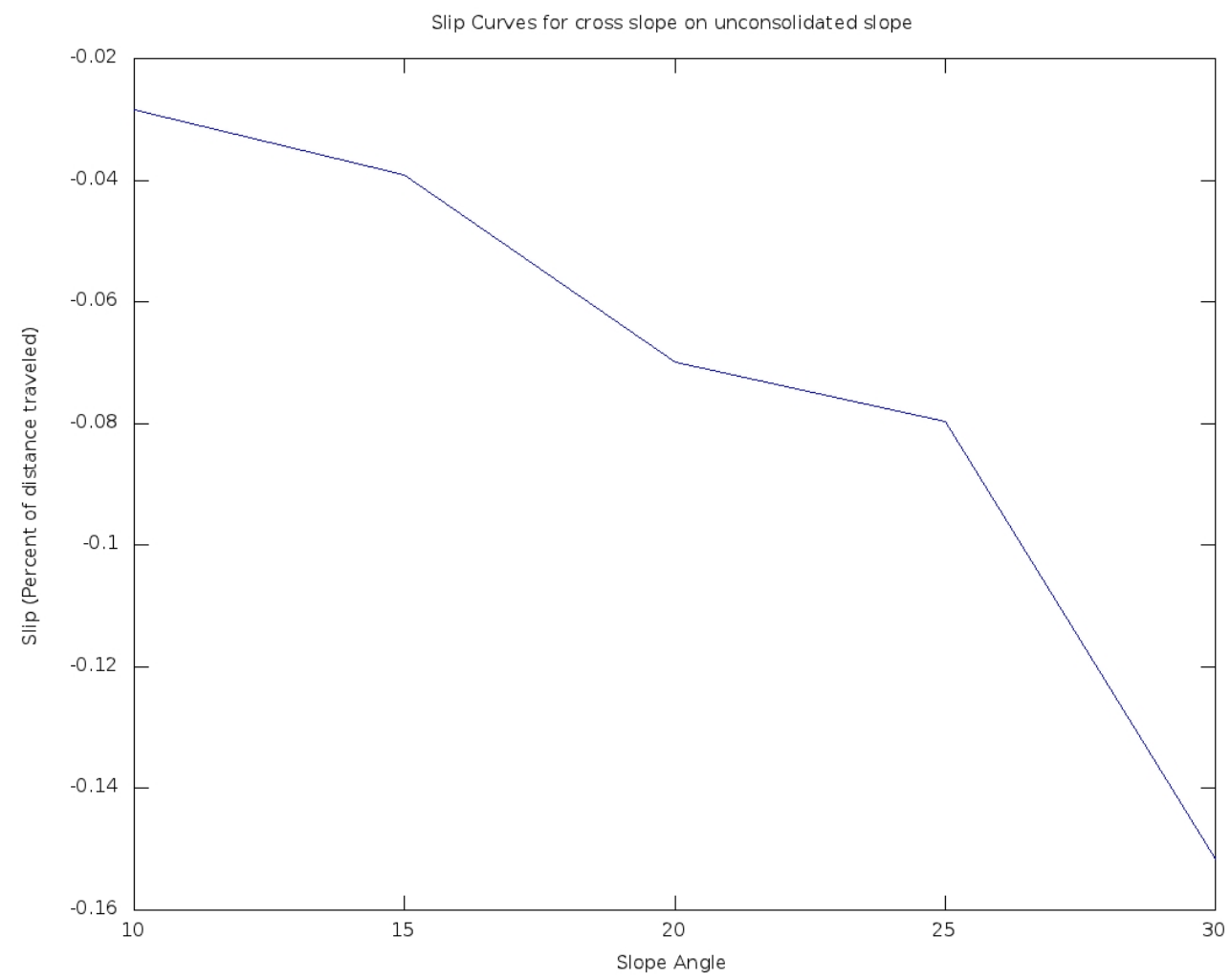

Figure 20: Cross slope plots. Note the y axis has a range of 0.18 percent

since Icebreaker only turned 90 degrees and the MER rovers were tested by turning a full 360 degrees. The MER rovers slipped about $250 \mathrm{~cm}$ while turning on a $20 \mathrm{degree}$ slope. Without a plow Icebreaker would do better, however with a plow, Icebreaker slips about $5 \mathrm{~cm}$ while turning on a 20 degree slope so would definitely be far superior as a turning platform [2].

\subsection{Summary}

The addition of the plow to the rover can clearly be seen to benefit mobility, above what can be achieved with just tractive ability. Using the plow reduces slip in a variety of situations that are important when traversing on extreme slopes. This is important as since mission planners can now develop plans for operating on steep slopes in order to meet objectives and to reach areas of interest. 


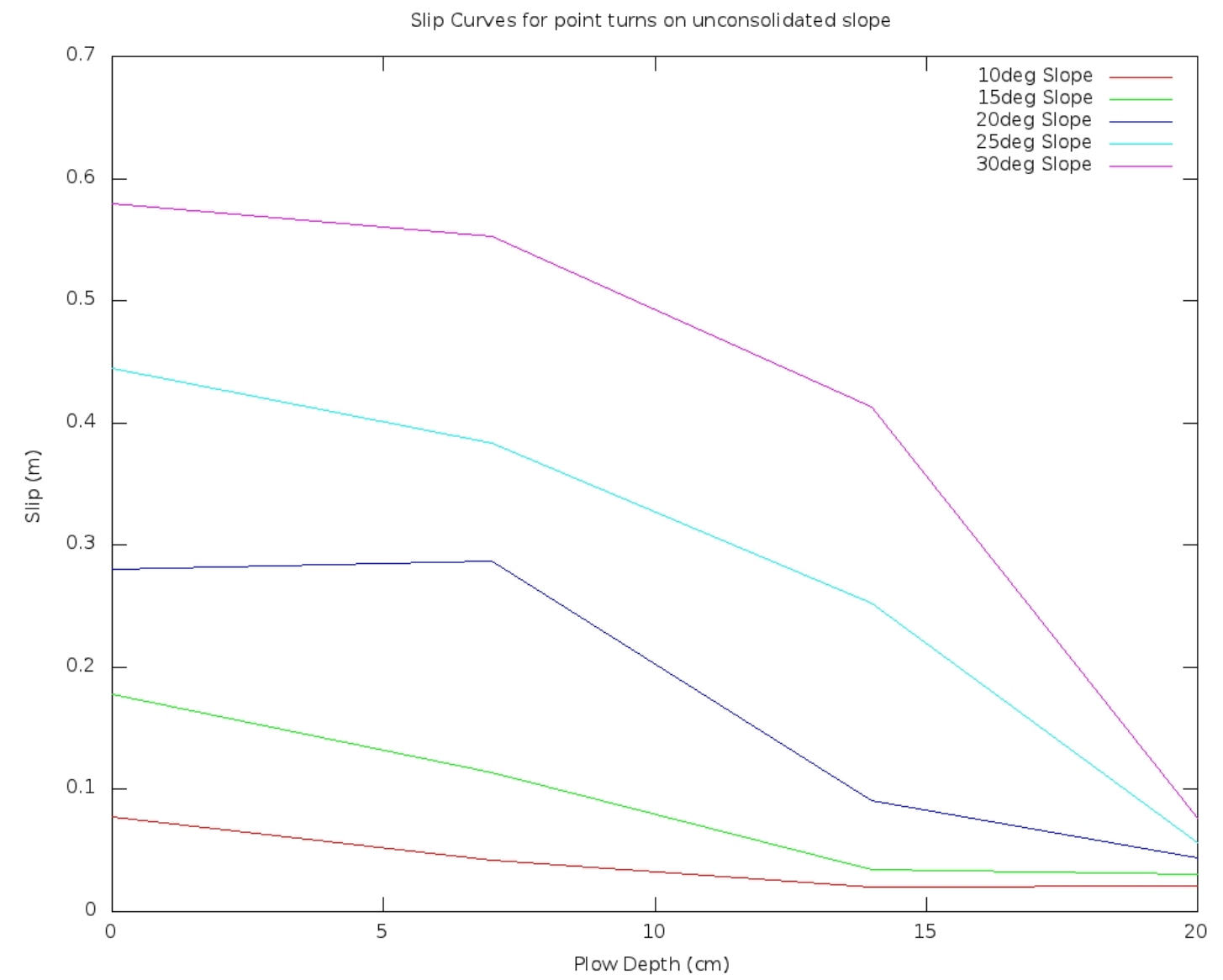

Figure 21: Point turns slip curves. 


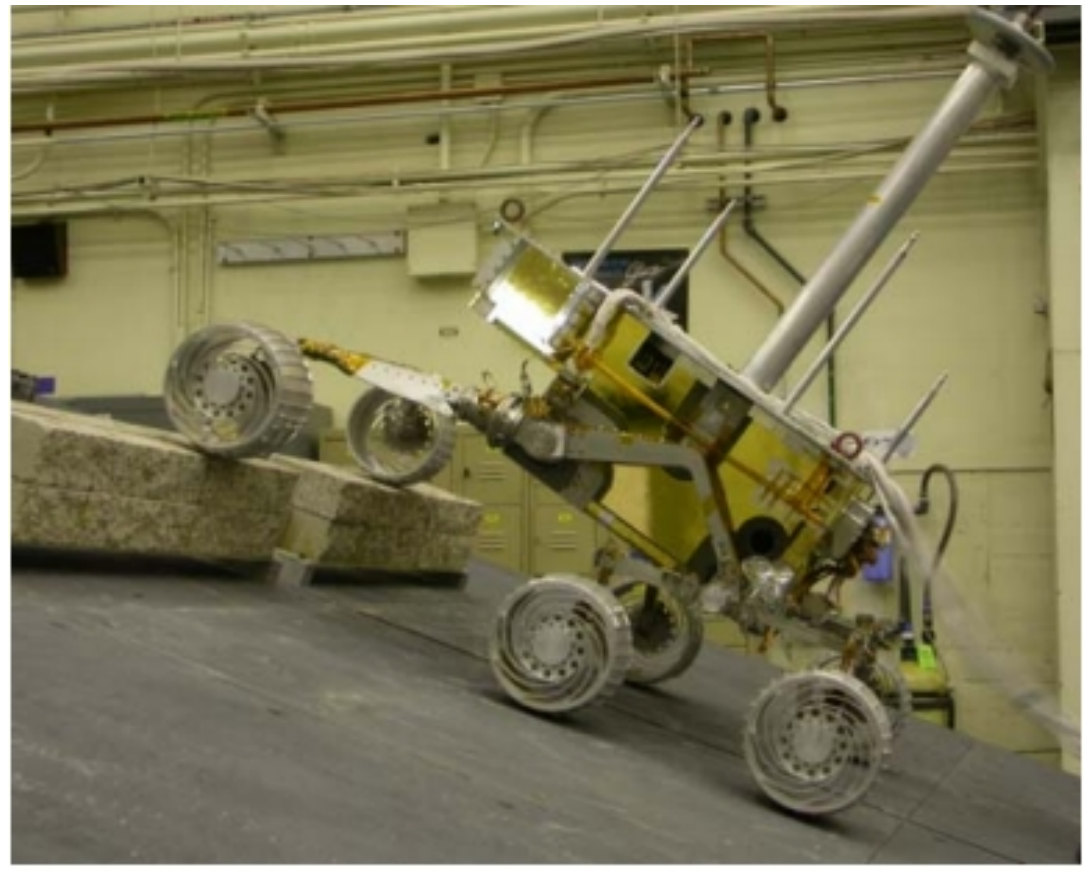

Figure 22: MER test model on a 20 degree slope navigating over $25 \mathrm{~cm}$ obstacles[2]. 


\section{Plow Analysis}

\subsection{Introduction}

In addition to rover testing this thesis examines the plow as a mechanism in order to develop the tool and to create a guide that future developers can use to design and evaluate the plow. This work focuses on the different variables that affect plow design independent of the vehicle.

\subsection{Experiment Design}

In order to quantify the plow performance, tests were conducted in the wheel test-bed at CMU (Figure 23 and Figure 24) [14]. These tests are designed to look at how the plow performance scales as the plow diameter changes and with plow depth. The wheel

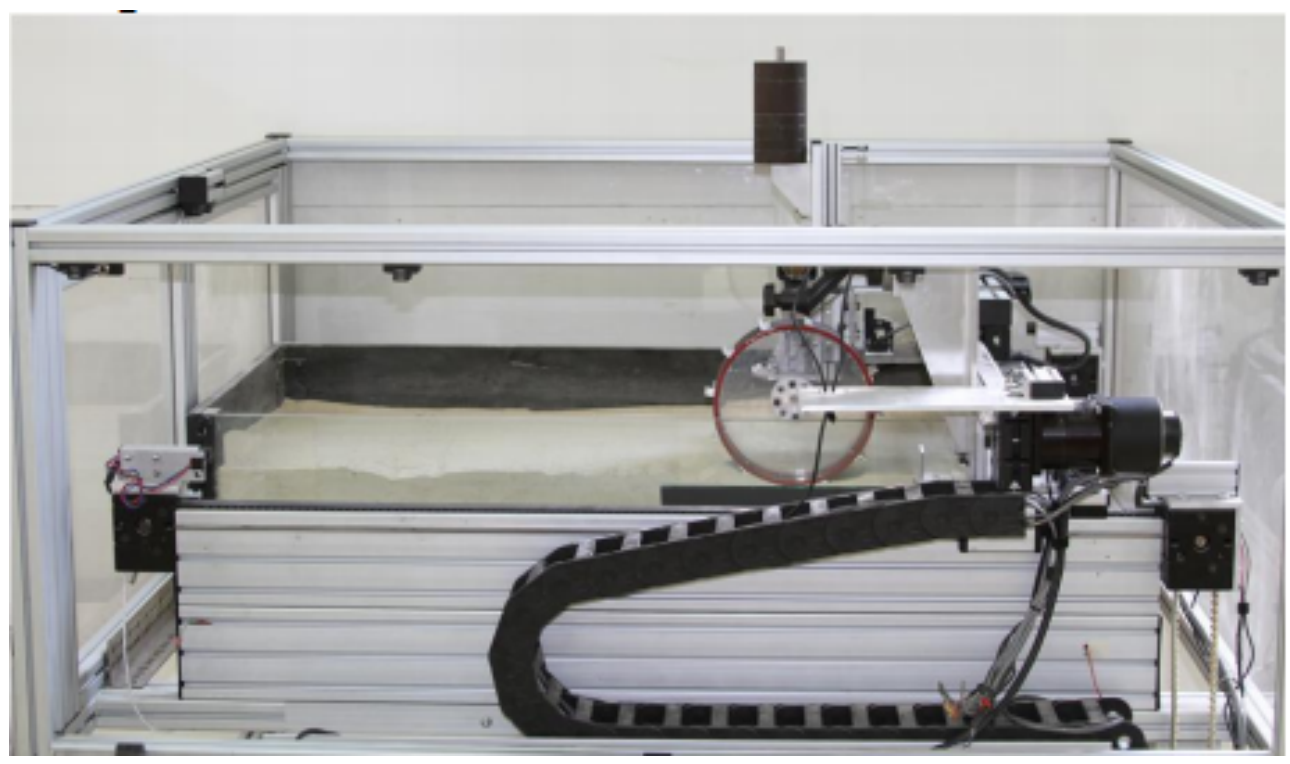

Figure 23: Wheel test bed rig at CMU used for plow testing [14].

test-bed has a sandbox filled with the GRC-1 lunar simulant that is prepared in a similar fashion to the large sandbox at the Glenn Research Center SLOPE facility before each test. In the sandbox a spade is used to loosen all of the subsurface sand and then it is lightly smoothed with the blade of a small dustpan. The wheel test-bed has a motor that can pull the plow at a constant velocity of $2 \mathrm{~cm} / \mathrm{s}$ and record the forces on the plow in the direction of travel with an ATI Delta Trasducer six axis force torque sensor. Tests were conducted with plows of 0.5 inch, 1 inch, and 2 inch diameter. A 3 inch plow was tested, however the forces were too large for the calibration range of the load cell (Figure 25). All of the plows were tested at $2.5 \mathrm{~cm}, 5 \mathrm{~cm}, 7.5 \mathrm{~cm}, 10 \mathrm{~cm}, 12.5 \mathrm{~cm}$, and $15 \mathrm{~cm}$ depth. A depth of $20 \mathrm{~cm}$ was attempted, however this exceeded the range of the 
load cell due to the torque placed on the load cell.

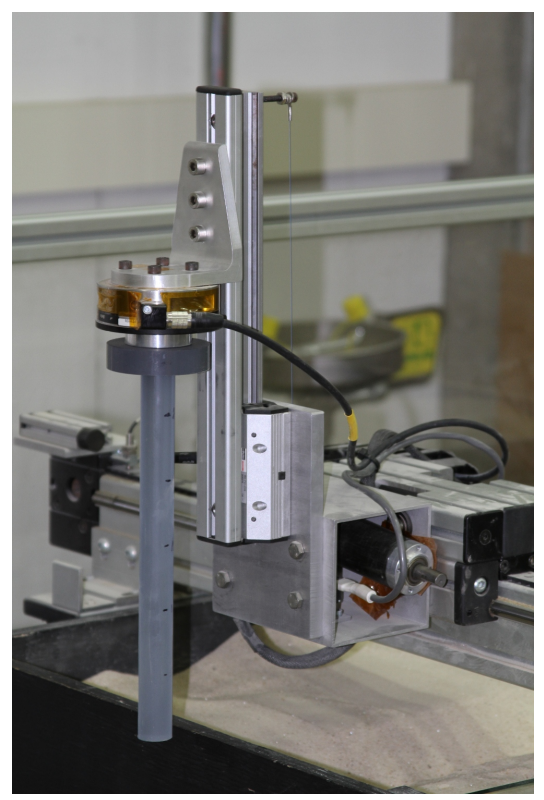

Figure 24: Closeup of test-bed mechanism with 1 inch plow attached.

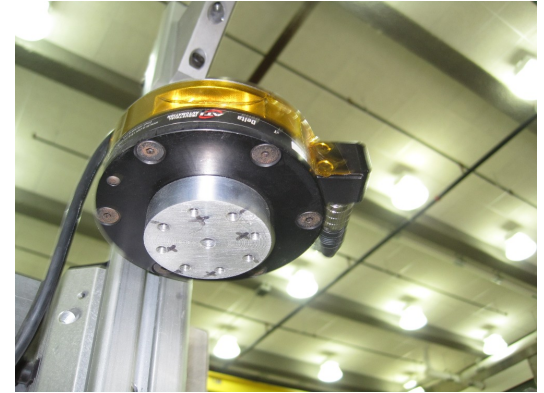

Figure 25: Six axis ATI Delta Transducer load cell used for the wheel test-bed.

\subsection{Model Results}

Using the Godwin model from Figure 8 critical depth (Table 2) and plow forces (Table 3 ) can be computed. There are several soil parameters that are needed for this model. The cohesion which is one of the most important parameters for predicting force is assumed to be $0 \mathrm{kN} / \mathrm{M}^{2}$ since the sand is heavely disturbed and unconsolidated. The friction angle is set to 35 degrees which is the average value for GRC-1. The Density is $10.7 \mathrm{kN} / \mathrm{M}^{3}$ which is standard for fine sands[10].

\begin{tabular}{|c|c|}
\hline Plow Diameter (inch) & Critical depth (inch) \\
\hline $0.5 ”$ & $1.57 ”$ \\
$1 ”$ & $2.76 "$ \\
$2 ”$ & $5.9 "$ \\
\hline
\end{tabular}

Table 2: Critical depth for a given plow diameter as predicted by the Godwin model.

\subsection{Experimental Results}

Testing done in the wheel test-bed is very informative and helps us understand how the plow works. One of the basic ideas that aligns with theory is that all of the track 


\begin{tabular}{|c|ccc|}
\hline Depth/Plow & 0.5inch & 1 inch & 2 inch \\
\hline $2.5 \mathrm{~cm}$ & 0 & 0 & 0 \\
$5 \mathrm{~cm}$ & 10 & 10 & 10 \\
$7.5 \mathrm{~cm}$ & 20 & 30 & 40 \\
$10 \mathrm{~cm}$ & 40 & 70 & 90 \\
$12.5 \mathrm{~cm}$ & 60 & 110 & 160 \\
$15 \mathrm{~cm}$ & 90 & 170 & 270 \\
\hline
\end{tabular}

Table 3: Force $(\mathrm{N})$ for a given plow depth $(\mathrm{cm})$ and plow diameter (inch) as predicted by the Godwin model (rounded to the nearest ten).

patterns formed from the plow cutting through the sand were an identical shape as can be seen in figures 26 and 27. The depth of the chevron shaped mark from the plow is roughly the critical depth as can be seen in table 4 . There is also a considerable amount of bulldozing at the front of the plow (Figures 28 and 29).

\begin{tabular}{|c|c|}
\hline Plow Diameter (inch) & Critical Depth (inch) \\
\hline $0.5 ”$ & $0.89 "$ \\
$1 ”$ & $1.31 ”$ \\
2" & $1.77 ”$ \\
\hline
\end{tabular}

Table 4: Critical depths for each plow tested.

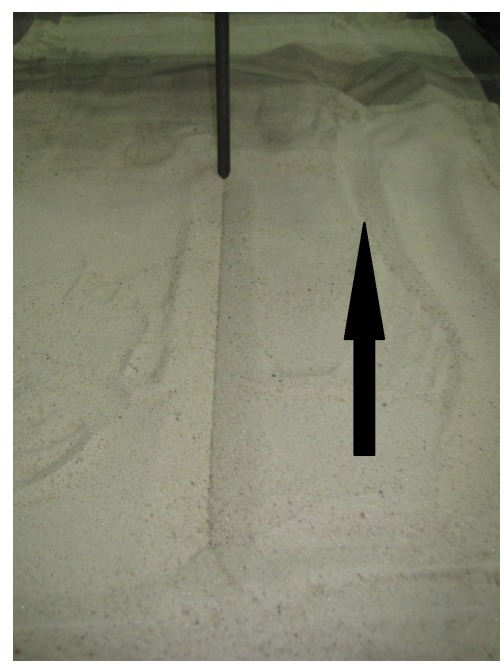

Figure 26: Shape of path created by 0.5 inch diameter plow. Black arrow shows direction of plow motion.

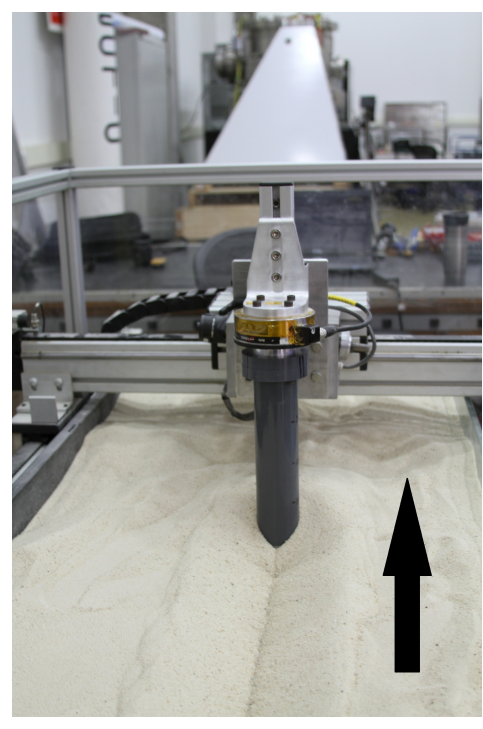

Figure 27: Shape of path created by 2 inch diameter plow. Black arrow shows direction of plow motion. 


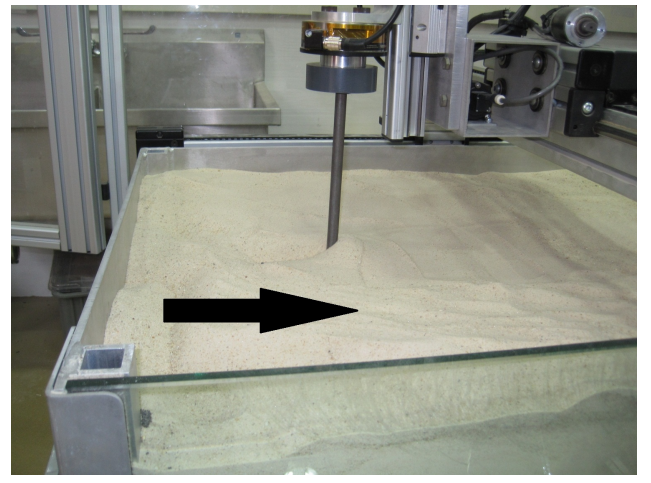

Figure 28: Bulldozing at end of 0.5 inch diameter plow. Black arrow shows direction of plow motion.

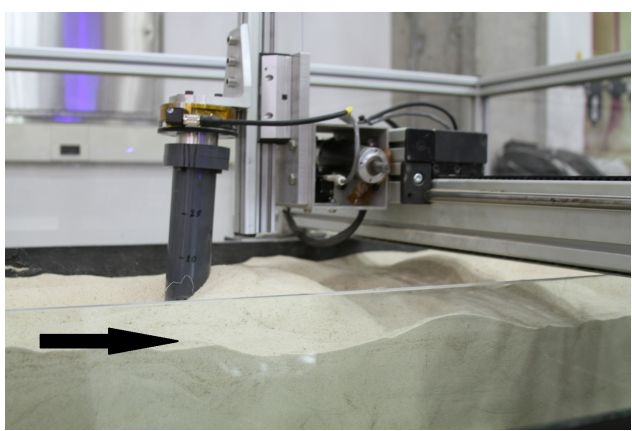

Figure 29: Bulldozing at end of 2 inch diameter plow. Black arrow shows direction of plow motion.

\begin{tabular}{|c|ccc|}
\hline Depth/Plow & 0.5 inch & 1 inch & 2 inch \\
\hline $2.5 \mathrm{~cm}$ & 1.96 & 2.47 & 2.56 \\
$5 \mathrm{~cm}$ & 5.25 & 4.69 & 20.25 \\
$7.5 \mathrm{~cm}$ & 19.12 & 21.70 & 54.46 \\
$10 \mathrm{~cm}$ & 23.61 & 45.13 & 75.45 \\
$12.5 \mathrm{~cm}$ & 53.49 & 86.35 & 130.56 \\
$15 \mathrm{~cm}$ & 65.90 & 111.01 & 143.49 \\
\hline
\end{tabular}

Table 5: Force (N) for a given plow depth (cm) and plow diameter (inch)

\subsection{Summary}

As expected increasing the plow diameter and/or increasing the plow depth showed an increase in braking force. Since all of these plows had a critical depth less than $2 \mathrm{~cm}$ a braking force is achieved at the shallowest depth tested of $2.5 \mathrm{~cm}$. For each plow the force at $15 \mathrm{~cm}$ depth increases by $10 \%$ as shown in table 6 . The model overestimated the critical depth and also the braking force of the plow. The force over estimates can be seen clearly in the larger depths and in Figure 31. This plow testing is important and usefull for engineers developing plowing systems. This work also illistrates the importance of real world testing and not only relying on models that are complex and have a large degree of error.

\begin{tabular}{|c|c|}
\hline Plow Depth & Percent Change \\
\hline 0.5 inch & 33 \\
1 inch & 45 \\
2 inch & 56 \\
\hline
\end{tabular}

Table 6: Percent force increase from $2.5 \mathrm{~cm}$ to $15 \mathrm{~cm}$ plow depth for each plow diameter 


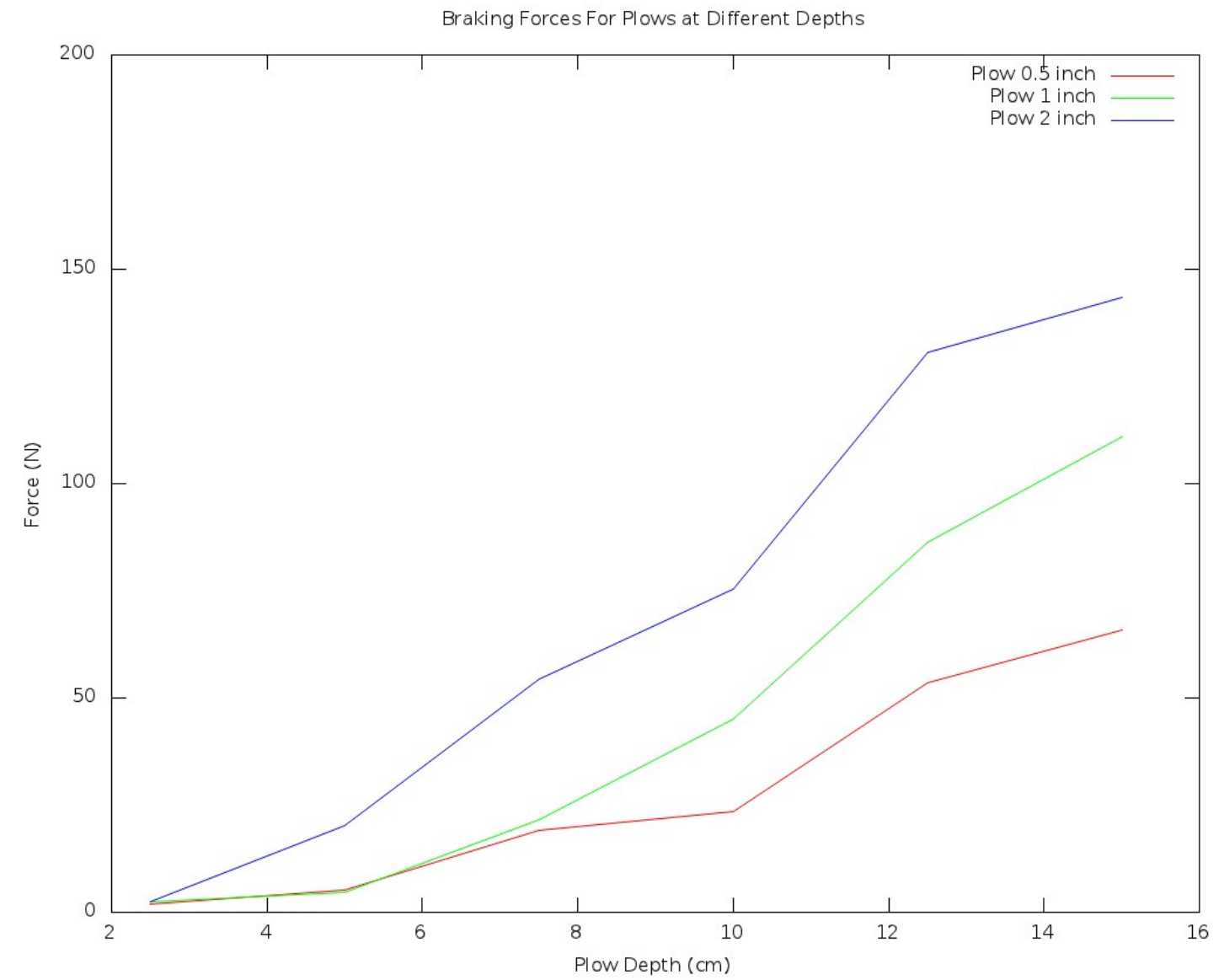

Figure 30: Force (N) for a given plow diameter at different depths. 


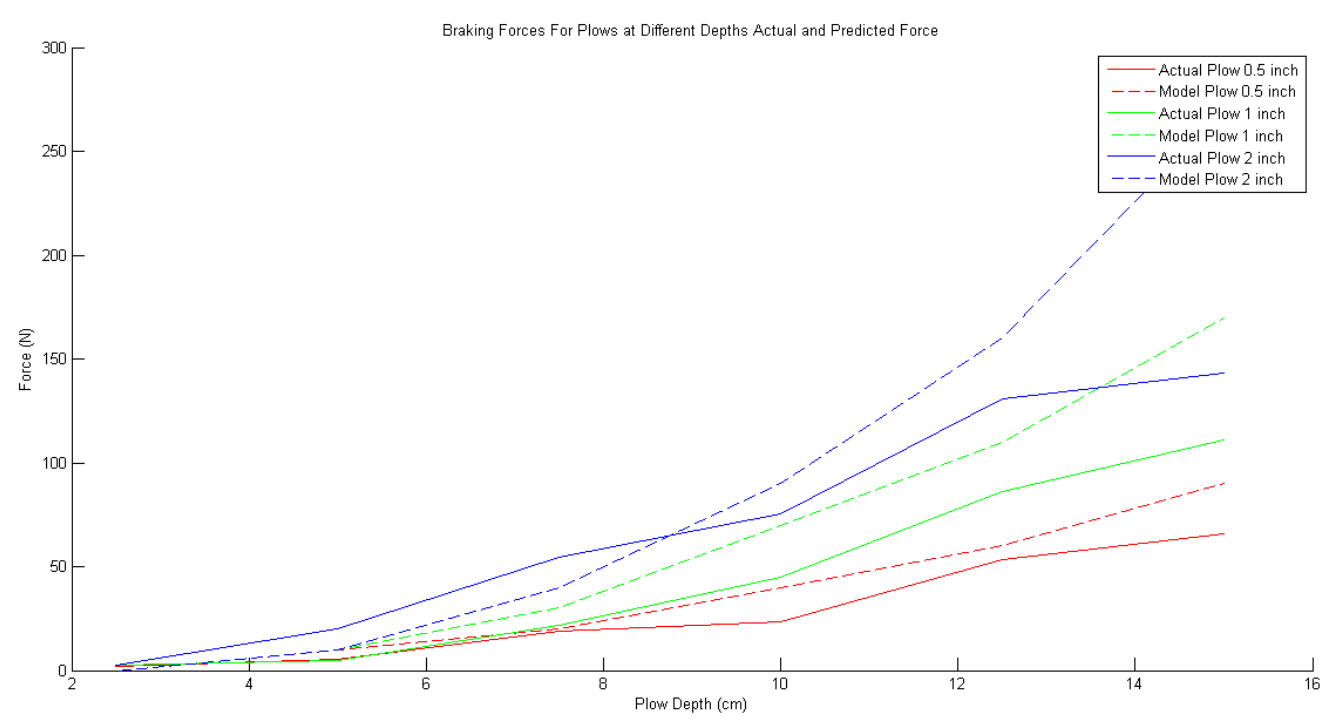

Figure 31: Force $(\mathrm{N})$ for a given plow diameter at different depths. Model predicted and actual. 


\section{Conclusion}

\subsection{Conclusions}

This thesis affirms quantitatively that plowing can be used in practice for control on extreme planetary surfaces that defy tractive descent. This work has shown a 7.5 fold reduction in slip when using the plow on 30 degree slopes as well as a complete reduction of slip on straight downhill descents on slopes up to 31 degrees. A new understanding of the plow teramechanics is now known based on a thorough review of farming literature and tine research. The trade offs of plow depth vs plow size has been explored. This gives the ability to design a plow and know what the braking forces will be. By using the plow we now have the ability to traverse into steep unconsolidated craters, canyons, funnels, and holes to explore both the slopes and the bottoms.

\subsection{Contributions}

This work has yielded many contributions to the fields of rover design and teramechanics. Plowing is a new method that mission planners can use when developing planetary rovers. Utilizing plowing and the results demonstrated in this thesis, scientists can visit crater walls which are of great scientific interest. Mission managers can now land at the top of the crater in visible terrain instead of having to land blindly in permanently shadowed craters. This work has also developed the tools to design a new plow system. Methods have been applied to plowing to understand where the forces are and how they scale with plow diameter and depth. This work resulted in data sets and an experimental method for designing and testing plows and rovers for extreme slopes. Teramechanics is traditionally thought of as either vehicle based or instrument based[11] [25]. This work has bridged the gap and demonstrates the interconnectivity of these two disciplines in novel ways.

\subsection{Future Work}

There are many ways that this work can be extended and future directions for this work to follow. I think the most important one is to further develop a reactive plow controller based on on-board slip estimation. The ability to estimate slip on the fly and react is critical to steep slope navigation. Initial results with these type of controllers look very promising. This work has focused on a uni-directional plow however there is a lot of work that can be done with a directional and steerable plow (similar to a boats rudder) this might give even better performance. Adding a science instrument to the plow can make the plow even more valuable. Some instruments that could be integrated are cone penetrometers, water detecting tuned laser diodes, a drill and many others. Another area to look at it is the tradeoff between mobility methods and power. In the course of this work we started to look at it and realized a lot more work is needed for this. 


\subsection{Acknowledgements}

I would like to thank the many people who have helped me get to this point. I would especially like to thank my wife for putting up with me as I did this research. My advisor David Wettergreen who has been a tremendous source of inspiration. Scott Moreland for his help with testing and for our many teramechanics discussions. William "Red" Whittaker for guiding me and introducing me to the exciting world of planetary robotics. Colin Creager, Vivake Asnani, and Ryan Gilligan at NASA Glenn Research Center for all of their help and insight in preparing these tests and evaluating Icebreakers performance. I would also like to thank all of the people who have been involved with Icebreaker since its inception including (but not limited to) Jason Zigler, Daniel Loret de Mola Lemus, and Phillippe Ayoub. 


\section{References}

[1] Issa A.D.Nesnas, Pablo Abad-Maneterola, Jefferey A.Edlund, and Joel W.Burdick. Axel mobility platform for steep terrain excursions and sampling on planetary surfaces. IEEE Aerospace Conferance, 2008.

[2] Randel A.Lindemann and Chris J.Voorhees. Mars exploration rover mobility assembly design, test, and performance. IEEE International Conferance on Systems, Man, and Cybernetics, 2005.

[3] John Bares and David Wettergreen. Lessons from the development and deployment of dante ii. Field and Service Robotics, December 1997.

[4] Paul Bartlett, David Wettergreen, and William(Red)L. Whittaker. Design of the scarab rover for mobility and drilling in the lunar cold traps. In International Symposium on Artificial Intelligence, Robotics and Automation in Space, February 2008.

[5] B.French, G.Heiken, and D.Vaniman. Lunar Sourcebook: A User's Guide to the Moon. Cambridge University Press, 1991.

[6] Glen Cushing and Tim Titus. Candidate cave entrances on mars, 2011.

[7] P.Michael Furlong, Thomas M.Howard, and David Wettergreen. Model predictive control for mobile robots with actively reconfigurable chassis. Field and Service Robotics, 62:469_ 478,2010

[8] R.J. Godwin. A review of the effect of implement geometry on soil failure and implement forces. Soil and Tillage Research, 97:331-340, 2007.

[9] G.Spoor and R.J.Godwin. An experimental investigation into the deep loosening of soil by rigid tines. J. agric. Engng Res., 23:243-258, 1978.

[10] Oravec H, Asnani V, and Zeng X. Design and charachterazation of grc-1:a soil for lunar terramechanics testing in earth-ambiant conditions. Journal of Teramechanics, 47(6):361377,2010

[11] D.R.P. Hettiaratchi. Theoretical soil mechanics and implement design. Soil and Tillage Research, 11:325-347, 1988.

[12] Genya Ishigami. Terramechanics-based Analysis and Control for Lunar/Planetary Exploration Robots. PhD thesis, Tohoku University, March 2008.

[13] Genya Ishigami, Akiko Miwa, Keiji Nagatani, and Kazuya Yoshida. Terramechanics-based model for steering maneuver of planetary exploration rovers on loose soil. Journal of Field Robotics, 24:233-250, March 2007.

[14] ScottJared Moreland, Krzysztof Skonieczny, David Wettergreen, Colin Creager, and Vivake Asnani. Soil motion analysis system for examining wheel-soil shearing. In International Conference of the International Society for Terrain-Vehicle Systems, September 2011.

[15] Tatsuro Muro. Tractive performace of a bulldozer running on weak ground. Journal of Terramechanics, 26:249-273, 1989.

[16] NationalSoilResourcesInstitute. A guide to better soil structure, 2001.

[17] R.J.Godwin and G.Spoor. Soil failure with narrow tines. J. agric. Engng Res., 22:213-228, 1977.

[18] R.J.Godwin and M.J.O'Dogherty. Integrated soil tillage force prediction models. Journal of Terramechanics, 44:3-14, 2007. 
[19] Shraga Shoval. Stability of a multi tracker robot traveling over steep slopes. IEEE International Conferance of Robotics and Automation, pages 4701-4706, 2004.

[20] J.V. Stafford. The performance of a rigid tine in relation to soil properties and speed. $J$. agric. Engng Res., 24:41-56, 1979.

[21] V.M.Salokhe and B.K.Pathak. Effect of aspect ratio on soil failure pattern generated by vertical flat tines at low strain rates in dry sand. J. agric. Engng Res., 53:169-180, 1992.

[22] V.V.Gromov and III W.D.Carrier. Mechanical properties of lunar soil and simulant. Enginnering, Construction, and Operations in Space, pages 518-527, 1992.

[23] David Wettergreen, Dominic Jonak, David Kohanbash, ScottJared Moreland, Spencer Spiker, James Teza, and William(Red)L. Whittaker. Design and experimentation of a rover concept for lunar crater resource survey. 47th AIAA Aerospace Sciences Meeting Including The New Horizons Forum and Aerospace Exposition, January 2009.

[24] J.Y. Wong. Theory of Ground Vehicles. Wiley, 1997.

[25] J.Y. Wong. Terramechanics and Off-Road Vehicle Engineering: Terrain Behavior, Off-road Vehicle Performance and Design. Oxford: Butterworth-Heinemann, second edition, 2010.

[26] AdamCharles Woodward. Experimental analysis of the effects of the variation of drawbar pull test parameters for exploration vehicles on grc-1 lunar soil simulant. Master's thesis, Virginia Polyttechnic Institute, June 2011.

[27] Jason Zigler. Rover configuration for exploring lunar craters. Master's thesis, Carnegie Mellon University, December 2007.

[28] Jason Zigler, David Kohanbash, David Wettergreen, and William(Red)L. Whittaker. Technolgies toward lunar crater exploration. Technical Report 0740, Carnegie Mellon University, 2007.

[29] Jason Zigler, David Kohanbash, David Wettergreen, and William(Red)L. Whittaker. Plowing for controlled steep crater descents. International Symposium on Artificial Inteligence, Robotics, and Automation in Space, 2008. 